\author{
Cadernos de \\ ESTUDOS LINGḯSTIICOS - (57.2), Campinas, Jul./Dez. 2015
}

\title{
APRAXIAS: CONSIDERAÇÕES SOBRE O CORPO E SUAS MANIFESTAÇÕES MOTORAS INESPERADAS
}

\author{
MELISSA CATRINI \\ UFBA/PUCSP \\ FRANCISCA LIER-DEVITTO \\ PUCSP \\ LÚCIA ARANTES \\ PUCSP
}

\begin{abstract}
RESUMO: O termo apraxia faz referência a uma perturbação do gesto, que envolve a dificuldade, ou até mesmo a impossibilidade, de realizar movimentos de maneira voluntária sem a presença de prejuízos musculares que justificassem o sintoma apresentado. Quando o gesto em questão é o articulatório, diz-se que é uma Apraxia de Fala. O caráter eminentemente funcional do problema leva ao questionamento, então, do que causaria tais sintomas. Apraxias têm manifestação no corpo e "corpo" é, por tradição e direito, objeto (exclusivo) do campo da Fisiologia e da Patologia - justificase, sem dúvida, a força da discursividade desses estudos sobre o tema que também opera no domínio da divisão filosófica mente/corpo - melhor entendido, da relação entre razão/cognição e corpo/ organismo. É na esfera do dualismo corpo-mente que se inscreve (a)praxia. No entanto, quando o dualismo psicofísico (Jackson,1866/1932) é dissolvido por Freud (1891), outra concepção de corpo deve vir a figurar nos estudos sobre as apraxias. Trata-se do corpo que é Um, aquele que nasce com o ser de linguagem, o falasser, o corpolinguagem (LACAN, 1985, 1998). O fenômeno apráxico coloca em relevo a relação entre corpo e linguagem. Este trabalho apresenta uma discussão teórica que parte da definição psicoanalítica de corpo.

Palavras-chave: apraxia; corpo; linguagem; sintoma na fala.
\end{abstract}

\begin{abstract}
Apraxia is the technical term, introduced in the medical literature, which names or designates motor disturbances whose manifestations are difficulties - or even the real impossibility - to perform voluntary gestures when there is no attested muscular damage to justify the observed motor symptom. When such a problem shows up in language usage, it is called Speech Apraxia. The outstanding functional character of Apraxia raises the issue concerning the causal factor of the symptomatic manifestations. The steady and unequivocal characteristic of Apraxia is the fact that it refers to strange gesture performances. Therefore, Apraxia occur in the body and, by tradition, "the body" leads us to the domains of Physiology, Pathology -- one can easily grasp the admitted strength and widespread diffusion of the medical discourse on Apraxia which, in fact, derive from the philosophic mind/brain dichotomy that allows for the hierarchical relationship boby $\rightarrow$ cognition or brain $\rightarrow$ mind. No doubt, apraxia is kept within the above mentioned dualistic discourse, despite the detour introduced by Freud (1891), who dissolved the so-called psychophysical dualism (Jackson, 1866/1932) and brought forward a new conception of body that should or might be considered when apraxia manifestations are at stake. Freud paved the way to the psychophysical dualism replacement. Indeed. A new conception of body, defined as effect of language could be theorized by Lacan (1985 e
\end{abstract}


1998). This paper endeavors to develop a theoretical discussion on speech apraxia taking into account the psychoanalytical conception of body.

Keywords: apraxia; body; language; speech symptom.

\section{INTRODUÇÃO}

Pacientes que chegam a Clínica de Linguagem com sérias dificuldades de fala ou mesmo que não podem falar levantam, por vezes, para o clínico, uma indagação sobre a eventual presença de uma apraxia, ou seja, de uma perturbação do gesto articulatório como possível obstáculo para a fala. No âmbito da Neurologia, da Neuropsicolinguística e da Fonoaudiologia, Apraxia de Fala é expressão que reúne um conjunto de alterações articulatórias e prosódicas que ocorrem sem que haja prejuízos musculares. Esta definição aponta, portanto, para desordens na fala promovidas por problemas eminentemente funcionais - é precisamente tal característica que a distingue da Disartria, descrita como problema que envolve alteração do controle muscular da fala. Entende-se, assim, o motivo da polêmica em torno da(s) causa(s) determinante(s) dos sintomas funcionais que a Apraxia de Fala coloca.

A explicação mais corrente é de natureza cognitivista, já que liga o problema a um déficit na programação motora dos movimentos requeridos para uma fonação ajustada e para a articulação apropriada de uma língua. De interesse é o fato de que a etiologia orgânica não é afastada completamente dessas abordagens de tonalidade mentalista. Na verdade, essa duas faces (orgânica e mental) aparecem como sendo perfeitamente compatíveis entre si: não há, nessas abordagens, estabelecimento de conflito entre o que se concebe como orgânico e como mental (Fonseca, 2003; Vasconcellos, 2010)․․ Fato é que o termo "programação" não recebe tratamento teórico refinado e a mecânica a ele suposta nem sempre é explicitada, sendo, desse modo, assumida (em sua vagueza) como evidente e autoexplicativa. A aproximação entre mente e cérebro parece tornar desnecessária qualquer explicação mais aprofundada sobre a estrutura e o funcionamento da mente/cognição. Talvez, por isso, haja uma notável unanimidade nas abordagens das apraxias no campo: todas, em algum grau, apoiam-se no discurso organicista sobre a relação mente-corpo. A extensa literatura sobre o assunto não encobre, porém, as muitas inquietações que essas desordens promovem.

Justamente, controvérsias e divergências entre autores e propostas chamam a atenção daqueles que se dirigem para o estudo das apraxias - médicos, psicólogos, fisioterapeutas, fonoaudiólogos são mobilizados pelo reconhecimento

${ }^{1}$ Para uma discussão em torno desse assunto, ver (Fonseca, 2002, Vasconcellos, 2010). As autoras abordam o uso de expressões como "comportamento voluntário", presentes no discurso médico, que implicam ou expõem a naturalização da articulação corpo-mente, que a visibiliza. $H$. Jackson (1866) é, também, uma referência importante no tratamento deste tema. De fato, não é sem razão que se afirme que as apraxias prejudicam a produção e sequenciamento voluntário de fonemas e que, por esse motivo, a terapia deva ter como centro treinos articulatórios e perceptuais para reordenar e fixar os gestos que estão distorcidos. 
do fenômeno apráxico que, mesmo quando clinicamente admitido, mantém sua condição de enigma, seja no que diz respeito à definição, seja à etiologia do problema. De um lado, testemunha-se nos trabalhos uma proliferação de tipos de apraxia numa extensa variedade: apraxia de marcha, apraxia nos movimentos requeridos para vestir-se, apraxia motora mais ampla, apraxia construtiva, apraxia do olhar, apraxia da fala, apraxia do desenvolvimento e assim por diante. O corpo vai sendo recortado e as apraxias nomeadas com base na observação de partes que apresentam disfunções. Essa proliferação de nomes, nos parece, é expressão de um apego maior à observação e descrição de quadros do que de um esforço de teorização sobre o problema. De outro lado, há questionamentos acerca da natureza do comprometimento neurológico: em algumas propostas, admite-se a presença de lesões neurológicas de diferentes dimensões e em localizações diversas; em outras vertentes, discute-se a possibilidade do problema ter determinação genética.

Não se pode negar - e não há quem negue - que a Apraxia faça signo de sua presença no corpo. Afinal, é de concordância geral e plena que manifestações das apraxias aparecem na movimentação de braços, pernas, laringe, boca, olhos, ou seja, no corpo. A questão que este trabalho levanta diz respeito, precisamente à questão: o que é "o corpo"?

\section{HUGHLINGS JACKSON E AS PRIMEIRAS CONSIDERAÇÕES SOBRE A APRAXIA.}

No âmbito do discurso médico, a discussão sobre a Apraxia tem como desbravador o neurologista H. Jackson. (1866/1932), que apresentou a primeira descrição de um paciente com esse distúrbio motor. Foi ele quem circunscreveu o quadro clínico de um problema em que o corpo fugia ao controle voluntário/ cognitivo da pessoa. Segundo o autor: "o paciente faz coisas involuntárias, que ele não pode fazer voluntariamente” (1866/1932, p. 123). E suas observações clínicas apontavam para uma intermitência de ocorrência de problemas de execução dos movimentos (inclusive da fala), o que, em si, atestava que as apraxias não eram alterações morfológicas ou estruturais. A explicação oferecida partiu da hipótese do paralelismo psicofísico ${ }^{2}$, introduzido e sustentado pelo próprio Jackson, que torna logicamente impossível a assimilação ou conjunção entre o psíquico/físico ou mental/orgânico - essas duas ordens são assumidas como caminhando em linhas paralelas, que não se encontram. Jackson enfatiza a radical separação entre corpo e mente (instâncias concomitantes, mas independentes) e pauta o entendimento das apraxias nesse paralelismo.

\footnotetext{
${ }^{2}$ A hipótese do "paralelismo psicofísico" trata da natureza da relação entre cérebro e mente. A doutrina que orienta o autor parte da premissa de que duas ordens de acontecimentos distintas não podem ser identificadas. A relação que se estabelece entre elas é de concomitância, ou seja, co-ocorrência, não havendo intromissão de uma sobre o funcionamento da outra. De acordo com Fonseca (2002), a reflexão de Jackson logicamente opõe-se ao pensamento causalista que orientou e orienta grande parte da Neurologia. É logicamente impossível estabelecer uma conexão causal entre acontecimentos diferentes, independentes e paralelos.
} 
Depois de Jackson (1866/1932), Steinthal (1871) e Liepmann (1900), respectivamente, o criador do termo "apraxia" e o autor cujo trabalho é considerado o "marco inaugural" dos estudos sobre esse quadro clínico, não se distanciaram da oposição corpo-mente: pela posição de destaque que lhes tem sido assegurada na história dos estudos sobre apraxia, seria de esperar que a mesma tendência explicativa persistisse em dias de hoje. De fato, os distúrbios apráxicos são abordados sob a égide do dualismo corpo $\rightarrow$ mente e, tendo em vista que não há prejuízo orgânico nesses quadros, o cognitivo ganha espaço e o problemas motores são vistos como uma patologia em que o corpo escapa ao domínio mental, i.e., esquemas de representações práxicas são dissolvidos. Nesse enquadre, o corpo biológico, como instância independente, pode ter sua matéria afetada - por uma lesão, por exemplo. A consequência disso seria um abalo na memória das representações mentais que impede a apresentação de respostas adaptadas a comandos: o corpo pode tornar-se massa desgovernada. Assim, os movimentos tornam-se "involuntários" e tudo aquilo que teria sido construído ao longo do processo de desenvolvimento resulta desordenado e fora de controle.

Quanto à construção de ações e condutas adaptadas, Piaget é expoente. Bem ajustado à epistemologia sujeito-objeto, ele procurou mostrar que as praxias são movimentos intencionais que dirigem o corpo para um objetivo. Trata-se de uma aquisição decorrente, de acordo com ele, da relação dialética entre a ação da criança e o mundo externo. De maneira geral, é a partir da divisão interno/externo que a Psicologia do Desenvolvimento (Piaget, Vygotsky ou Wallon) desenvolve a explicação clássica sobre o advento do sujeito epistêmico (LEMOS, 1982, 1986; PEREIRA DE CASTRO, 1992; LIER-DEVITTO, 1994/1998). Em outras palavras, o dualismo mente-corpo orienta a epistemologia sujeito-objeto. Podemos dizer, assim, que tanto as praxias quanto sua versão sintomática, as apraxias, têm sido tradicionalmente inscritas na esfera deste dualismo. Este artigo assume posição crítica frente a tal vertente argumentativa, pois entende que a manutenção de um raciocínio dualista, do tipo corpo-mente, aprisiona a explicação para ocorrências apráxicas num círculo vicioso em que ora a explicação fica radicalmente circunscrita à etiologia orgânica, ora é remetida a desordens cognitivas.

Jackson (1866), embora tendo se declarado "médico" e, portanto, comprometido com o corpo/organismo, pode iluminar direções inusitadas na reflexão sobre a Apraxia. Interessa dizer que Freud $(1891,1893)$ não foi absolutamente indiferente à obra do autor. Freud reconhece o gesto teórico de Jackson e, tendo operado a dissolução do paralelismo psicofísico, ao substituir sua fórmula como o reflexo de duas esferas "concomitantes independentes" por outra fórmula que as apresenta como "concomitantes dependentes", introduz uma figura de corpo bastante diferente daquele suposto nos trabalhos que não se afastam da epistemologia sujeito-objeto ${ }^{3}$. No caso, aparece, em Freud, um corpo em que psíquico e físico "... se corrompem um ao outro" em expressão de Milner (1978/1987, p. 61).

\footnotetext{
${ }^{3}$ Recomendamos, sobre isso, a leitura de Fonseca, S. (2002).
} 
2. CORPO FALADO, FALASSER

A figura de "corpo" que Freud erige "psíquico" não corresponde a "mental/ cognitivo" e sua incidência teórica no par psico-físico de Jackson representa, a rigor, uma antecipação da revolução e da novidade que o conceito de inconsciente produzirá: ele afasta o dualismo orgânico-mental, que fica definitivamente eliminado do pensamento psicanalítico. Para Freud, o corpo fala (FREUD, 1983/2005). Devemos admitir que, sob tal teorização, a Apraxia não caberia numa explicação que a circunscrevesse à distinção entre movimentos voluntários e involuntários.

Neste artigo, aproximamo-nos do discurso psicanalítico, que toma distância do discurso organicista, que se articula com o aporte cognitivista. Bergès (1967/1972 e 1986/1997) é apoio para uma discussão sobre o corpo que envolva a relação entre estrutura, função e funcionamento. Assinalamos que a Apraxia aponta para sintomas com perfil funcional (e não estrutural). De um ponto de vista neuropsicológico, a relação estrutura, função e funcionamento é abordada do seguinte modo. Afirma-se que:

- toda função supõe uma estrutura orgânica como suporte;

- a maturação da estrutura torna possível certo nível de funcionamento, e,

- com isso, há evolução da função.

Tal funcionamento está em franca relação com o externo. No caso das praxias, afirma-se que a maturação de estruturas (do Sistema Piramidal, em especial) dará suporte à função motora e a sua posterior evolução. Nesse ambiente teórico, sustenta-se, também, que há formação de uma imagem corporal como efeito da dialética interno-externo, suposta ao funcionamento da função motora. A "imagem corporal" seria instituída, organizada e aperfeiçoada pela ação do corpo sobre o espaço e os objetos: "[nesse] jogo, a motricidade torna-se uma praxia, que redunda no gesto" (BERGÈS, 2005/2008, p. 32). Frente a esse quadro, Bergès pergunta: "a questão radical que Freud propõe [sobre isso] é a seguinte: quanto à satisfação, ela está aí ou não está? O prazer, ele esta aí ou não, neste intercâmbio de bons procedimentos entre função, estrutura e funcionamento?" (BERGÈS, 2008, p.32) (ênfases nossas). Bergès aponta, com isso, para um espaço de indeterminação e imprevisibilidade entre função e funcionamento (FERREIRA, 2006), ou seja, para ele, o modo como uma estrutura é posta a funcionar envolve mais do que um processo maturacional determinado geneticamente; envolve a afetação subjetiva da ação/olhar do outro sobre o corpo da criança.

Bergès interroga, de fato, o pensamento organicista presente na interpretação da relação entre estrutura-função-funcionamento ao introduzir, ali, determinantes psíquicos (satisfação e prazer). Em O Gesto e a Personalidade (1967/1972), Bergès acrescenta que, se a possibilidade de movimento depende de uma competência estrutural do corpo para a motricidade (inervações, ossos e músculos), o gesto, diferentemente, mostra que há sentido no movimento, i.e., o gesto pertence ao campo das significações - mais precisamente, ao campo da linguagem, mesmo 
que o homem não se dê conta disso, mesmo que ele "não saiba nada disso" (BERGÈS, 1967/1972), seus gestos exprimem algo absolutamente pessoal, são verdadeiras "maneiras de fazer", "maneiras de dizer", "maneiras de ser" eles são radicalmente singulares. Isso porque, esclarece o autor, algo incide no movimento e o gesto (satisfação, prazer...) - "algo" que ele chamou, com Freud, de personalidade.

Bergès, antes de psicanalista, psiquiatra e neurologista, foi tocado por questões relativas ao sujeito e à linguagem nas considerações sobre o corpo. Em palavras suas: "[o equívoco], quando se trata de corpo, [é] o de que haveria, antes da linguagem e ao lado desta, uma modalidade de expressão mais primitiva, mais pura, porque corporal" (BERGÈS, 1986/1997, p.51) (ênfases nossas). A expressão corporal é, segundo ele, efeito de linguagem - decorre do "olhar do outro" (do toque e da interpretação), i.e., está ligada tanto ao modo de olhar/tocar do outro, quanto a como a palavra chega à orelha. A motricidade do corpo está engastada, sustenta Bergès, na palavra - na busca de sentido para o corpo e no apelo por amor.

Assim, conclui Bergès, o sujeito quer ser amado no órgão de sua gestualidade, pois: "o corpo é, antes de mais nada [antes da voz], um receptáculo, um lugar de inscrição, uma trama implacavelmente destinada a imprimir-se com os cenários, as cores de outrem, a começar pela servil cópia do motivo" (BERGÈS, 1986/1997, p. 51) (ênfase nossa). Esse "outrem" em Bergès, outro-falante - outro que é fonte de sentido, lugar em que se deposita o apelo por amor, como vimos. O autor desloca, redefine a concepção de um corpo receptáculo conforme concebido em trabalhos de base piagetiana, em que a noção vem ligada "a um engrama genético sustentando uma competência inata” (BERGÈS, 1986/1997, p. 52), que receberá influências externas.

A dialética entre interno-externo está implicada na obra de Piaget. Ele ensina que um organismo que se constituirá num corpo através da ação da criança sobre o mundo e de seus efeitos (do mundo) nela. Em Ajuriaguerra ${ }^{4}$, esta dialética caminha no sentido de incluir a ação do outro social na formação do corpo, do esquema corporal $^{5}$. Bergès, no entanto, envolve o outro-falante, como vimos - assim, entre a ação da criança e a do outro, estão o desejo e a linguagem. O autor não se satisfez com a explicação de que a imaturidade do organismo ao nascimento demandaria a ação do outro - nessa relação falta a linguagem.

Indicamos, acima, que Freud, ao postular a "concomitância dependente" entre os domínios psíquico e físico, dissolve do paralelismo (dualismo) e abre caminho para uma nova concepção de corpo. Nos escombros da histeria e nos furos da afasia, Freud viu que estrutura e funcionamento não caminham lado a lado. Bergès esclarece: "em neurologia, procura-se, habitualmente, a incompetência

${ }^{4}$ Bergès se desliga as praxias da determinação orgânico-cognitiva, que afasta a linguagem. Utilizando uma expressão de Ajuriaguerra (que entendia ser o corpo um "receptáculo" de informações de experiências sensório-motoras e cognitivas) Bergès (2005/2008) redireciona a resposta ao perguntar, outra vez: "o corpo é receptáculo do quê?

${ }^{5}$ Esta seria, convém assinalar, a alegada diferença entre Vygostsky ou Wallon e Piaget. 
da estrutura" (2005/2008, p. 38). O corpo na Psicanálise, interroga o autor, não levantaria a questão da incompetência da função em relação ao funcionamento? O ponto aqui é o quanto o corpo real é competente para sustentar o significante.

Para agir, o corpo deve ser emoldurado, capturado pelos ritmos e pelo olhar do outro. Bergès (1998b) ensina que o saber da mãe - sua teoria sobre a criança - pode constituir, ou não, o corpo como suporte das inscrições significantes, isto é, pode pôr a estrutura a funcionar ou a (dis)funcionar. O elemento primeiro é o grito do recém-nascido, que é logo promovido à condição de significante. Nele, no grito do recém-nascido "é o desejo como tal que a mãe, enquanto sujeito, deve reconhecer" para, assim, pôr um corpo a funcionar (BERGÈS, 1986/2008, p. 129). O corpo real da criança é imaginarizado e simbolizado pela mãe.

Bergès parte do princípio de que o corpo não é unicamente receptáculo do que vem do mundo exterior, mas o suporte da inscrição significante que o constitui ao inseri-lo na ordem simbólica. Assim, devem ser considerados os diferentes efeitos que a presença viva da criança produz sobre o outro e sobre o olhar e a escuta que ele poderá oferecer a ela ${ }^{6}$.

Ferreira (2006) assinala que, nos Três Ensaios sobre a Teoria da Sexualidade, Freud (1905) reconhece, nos cuidados que a mãe dedica ao seu bebê, um "trânsito sexual", já que toque e carícia erotizam partes do corpo da criança. A autora acrescenta uma observação essencial: "essa cena entre a mãe e a criança não é uma cena muda" (FERREIRA, 2006, p. 34). Isso significa que a fala da mãe envolve a cena, dá seu contorno e sentido - a mãe introduz o simbólico que banha o bebê. É nessa relação tão íntima e especial que o corpo é capturado pela linguagem.

Bergès (2005/2008) pontua que o aparecimento da fala implica uma perda. Segundo o autor, os bebês nascem com estruturas orgânicas para pronunciar os sons/fonemas de todas as línguas ${ }^{7}$ - essa "competência", é bom frisar, não tem o sentido que Chomsky confere ao termo (não se trata de conhecimento linguístico inato). Trata-se de uma potencialidade motora de articulação, que é restringida e mesmo "perdida" quando o corpo é capturado por uma língua. Para ele, este é o maior exemplo ou manifestação mais expressiva de perda da função por falta de funcionamento. Segundo Bergès, este fato mostra que, seja por perda sináptica, seja por influência do externo ou por efeito de recalcamento, é a linguagem que impõe restrições e limites ao organismo.

A potencialidade motora, de que fala Bergès, tem relação com o fato de que nosso aparato orgânico não vem equipado com um "aparelho fonador" e programado para produzir fala articulada. O corpo é aparelhado depois - quando a ordem simbólica toca e faz marcas no corpo real e constitui o fala-ser, como diz Lacan. Entende-se, assim, a afirmação de Vorcaro (1999, 2003, entre outros) de

\footnotetext{
${ }^{6}$ Por exemplo, quando o olhar é surpreendido por falhas no corpo real da criança, a mãe enfrenta algo contrário e resistente ao seu imaginário, e com isso, a inscrição no simbólico fica ameaçada. Bergès afirma que, nessas circunstâncias, a mãe recua frente à linguagem. Sobre isso ver Catrini (2011).

Bergès fala aqui das malformações, doenças genéticas, feridas, traumas, lesões, paralisia cerebral, etc.

${ }^{7}$ Também Jakobson (1940) tem esta mesma posição sobre ontogênese da fala.
} 
que "a incidência da matriz simbólica no organismo é condição necessária para o advento da fala". Frente a tal afirmação, é impossível assimilar corpo-pulsional (corpo-falante) a organismo e, ao mesmo tempo, distinguir com perfeita nitidez organismo e corpo pulsional (corpo-falante). É tal complexidade que se apresenta quando a questão do corpo é central, como no caso das apraxias. A Clínica de Linguagem testemunha, cotidianamente, que o corpo do ser que fala não é redutível a um substrato orgânico isolado (a corpo-real). Os sintomas na fala levantam, com frequência, uma questão sobre o corpo e desafiam o dualismo corpo-mente, por colocarem em evidência o fracasso cognitivo de um sujeito frente a uma faltafalha [que] ele nada pode fazer para mudar (LIER-DEVITTO, 1999, 2000, 2003, 2006), e nem pode, muitas vezes, incidir sobre os efeitos que ela venha a produzir no outro.

$\mathrm{O}$ atendimento de um paciente (senhor P.) pode mostrar muito bem a natureza peculiar de uma escuta para a própria fala (sintomática). De maneira resumida: o senhor P. falava muito e era fluente: na maioria das vezes, nesta fala emergiam articulações inesperadas e fragmentos desajustados ao texto em andamento que, por isso, promoviam desordens coesivas e rupturas abruptas da direção discursiva. Contudo, o paciente não parecia dar-se conta dessas ocorrências perturbadoras. Surpreendente era, ainda, que, em certos momentos, nessa "falação" do senhor P., a acima referida fluência era estancada por um movimento circular em torno de uma quase-palavra (como em torno de "Derdic", sigla da instituição em que foi atendido: “É, $a$, a é i ( ) é $a$ ( ) $a-b-c-d$... dedif, de-defi (SI)"). Nesses momentos, sua fala ficava ali, um bom tempo, mobilizada por um gesto motor que não se decidia, mas que parecia afetado por sons que restringiam o compasso de seu enunciado e os gestos motores. Nessas ocasiões específicas, o senhor P. ignorava, por assim dizer, as entradas da terapeuta, que buscava reconduzi-lo ao texto dialógico. Situação estranha: quando ele assumia uma posição no diálogo clínico e endereçava sua fala para a terapeuta, ela fluía sem restrição, mas, também, sem destino discursivo. Diferentemente, quando ele parecia escutá-la (havia hesitação e escansão - intervalo entre fragmentos), ele não abria espaço para o outro ("não escutava' a fala desse outro), como discutiu Catrini (2009). Importa assinalar, aqui, que em um ou em outro caso, o paciente não podia contar com qualquer recurso cognitivo para reordenar e organizar seus enunciados.

Esse tipo de acontecimento na fala é, com frequência, identificado a uma descontrole na programação do ato motor da fala, ou seja, de Apraxia de fala. Dizse que o paciente sabe o que quer dizer, que antecipa sua dificuldade articulatória e, por isso, fica aprisionado na tentativa de acertar o gesto. Contudo, esse interpretação pode ser colocada sob suspeição frente a casos como o do senhor P., em que há marcante flutuação na escuta do paciente. Menos do que antecipar uma dificuldade articulatória, o sujeito era "pego" por ela e incapaz de evitar os gestos desajeitados que a fala e seu corpo lhe impõem.

A distinção entre ouvir/escutar é fundamental aqui: "ouvir é fenômeno fisiológico, mas escutar envolve 'interpretação', um efeito da linguagem no corpo" (VASCONCELLOS, 2006, p. 290), ou melhor, escutar é efeito da articulação sujeito-língua-fala (ANDRADE, 2003), que não vem “depois”, mas que se instala 
no nascimento. Para o humano, não haveria, portanto, uma linha divisória entre organismo e corpo-falante - há "falasser", como diz Milner (1978/1987) a partir de Lacan, i.e., há "corpolinguagem" (GP Semasoma) - o corpo é Um, disse Lacan. No caso da Apraxia de Fala, parece importante perguntar: "o que é o dito aparelho fonador"? É um aparelho que se organiza por efeito da incidência da fala no corpo. Este aparelho tem como apoio órgãos que, de um ponto de vista organicista, estão a serviço dos aparelhos digestivo e respiratório. Desse modo, o que faz um corpo falar é uma língua falada por outros. Trata-se, nessa perspectiva, de um corpo "capturado" (DE LEMOS, 1992, 2002, 2007), incluindo aí a orelha que "escuta" e boca que "fala" (ANDRADE, 2003 e outros). Nesta direção, dissolvese a dicotomia mente-corpo, que pode abrir caminho para outra teorização sobre as apraxias. Foi o que procuramos discutir.

\section{$\overline{\text { REFERÊNCIAS BIBLIOGRÁFICAS }}$}

ANDRADE, L. Ouvir e Escutar na constituição da clínica de linguagem. 2003. 143f. (Doutorado em Linguística Aplicada e Estudos da Linguagem) - Pontifícia Universidade Católica de São Paulo, São Paulo. Inédito.

BERGÈS, J. Os Gestos e a Personalidade. Rio de Janeiro: Editora Civilização Brasileira, 1967/1972.

BERGÈS, J. O corpo e o olhar do Outro. In: Escritos da criança, Porto Alegre, n. 2, 2 ed., 1986/1997, p. 51-65.

BERGÈS, J. O corpo na Neurologia e na Psicanálise: lições clínicas de um psicanalista de crianças. Porto Alegre: CMC Editora, 2005/2008.

CATRINI, M. Afasia e Apraxia de fala: o que dizer da relação sujeito-linguagem? (Trabalho apresentado no 17 InPla, Pontifícia Universidade Católica de São Paulo), 2009.

CATRINI, M. Apraxia: sobre a complexa relação entre corpo e linguagem. 2011, 135f. (Doutorado em Linguística Aplicada e Estudos da Linguagem) - Pontifícia Universidade Católica de São Paulo, São Paulo. Inédito.

DE LEMOS, C. A Sintaxe No Espelho. Cadernos de Estudos Lingüisticos. Campinas: UNICAMP/ IEL - setor de publicações, vol.10, 12-28, 1986.

DE LEMOS, C. Los Procesos Metafóricos Y Metonímicos como Mecanismos de Cambio, In: Substratum, vol.1, n.1, Barcelona: Melder, 1992, p. 121-135.

DE LEMOS, C. Das vicissitudes da fala da criança e de sua investigação. Cadernos de Estudos Linguísticos, Campinas: Unicamp/IEL - Setor de Publicações, vol.42, 2002.

DE LEMOS, C. Da angústia na infância. In Literal, n. 10, 2007, p. 117-125

FERREIRA, M. T. Como a palavra é tomada no corpo? In: Literal, n. 9, 2006, p. 33-48.

FONSECA, S. O Afásico na clínica de Linguagem. 2002. 264f. (Doutorado em Linguística Aplicada e Estudos da Linguagem) - Pontifícia Universidade Católica de São Paulo, São Paulo. Inédito. 
FREUD, S. La Afasia. Buenos Aires: Ediciones Nueva Visión, 1891/1987.

FREUD, S. Estudio comparativo de las paralises motrices orgânicas e histéricas. In. FREUD, Sigmund. Obras Completas, Buenos Aires: Editorial Ateneo, Tomo 1, 1893/2005, p.13-21.

JACKSON, H. Notes on the physiology and pathology of language. In: TAYLOR, J. (ed.). Select Writings of John Hughlings Jackson, London: Hodder and Stoughton, v. 2, 1866/1932, p. 121128.

JAKOBSON, R. Lenguaje Infantil y Afasia. Editora Ayuso: Buenos Aires, 1940/1971.

LACAN, J. O seminário, livro 11: os quatro conceitos fundamentais da psicanálise (1964). 4. ed. Texto estabelecido por Jacques-Alain Miller. Rio de Janeiro: Jorge Zahar, 1990.

LACAN, J. Subversão do sujeito e dialética do desejo no inconsciente freudiano (1960), p. 807-842. In Escritos. Rio de Janeiro: J.Zahar, 1998.

LIEPMANN, H. Das Krankheitsbild der Apraxie (motorische Asymbolie) auf Grund eines Falles von einseitiger Apraxie. In: Monatschr. Psychiat. Neurol., 8, 15-44, 102-132, 182-197, 1900.

LIEPMANN, H. Der weitere Krankheitsverlauf bei dem einseitig Apraktischen und der Gehirnbefund auf Grund von Serienschnitten. In: Monatschr. Psychiat. Neurol., 17, 289-311; 19: 217-253, 1905 .

LIER-DEVITTO, M. F. Os Monólogos da Criança: Delírios da Língua. São Paulo: Educ, 1994/1998.

LIER-DEVITTO, M. F. Theory as a ideology and approache to deviant linguistic facts, In: JEFF VERSCHUEREN (ed.). Language and Ideology, Bélgica: IPRA, vol. 1, 1999, p. 344-351.

LIER-DEVITTO, M. F. As Margens da Linguística. Relatório de bolsa produtiva em pesquisa (CNPq.), 2000.

LIER-DEVITTO, M. F. Patologias da Linguagem: subversão posta em ato. In: LEITE, N. (org.) Corpolinguagem; gestos e afetos. 1 ed. Campinas, v. 1, p. 233-246, 2003.

LIER-DEVITTO, M. F. Patologias da Linguagem: sobre as "vicissitudes de falas sintomáticas". In: LIER-DEVITTO, M. F. \& ARANTES, L. (org). Aquisição, Patologias e Clínica de Linguagem. São Paulo: EDUC, 2006, p. 183-200.

MILNER, J.C. O Amor da Língua. Porto Alegre: Artes Médicas, 1978/1987.

PIAGET, J. Les praxies chez l'enfant. In: Rev. Neurol. (Paris), v. 102, 1960, p. 551-565.

STEINTHAL, H. Abriss der Sprachwissenschaft. In: Einleitung in die Psychologie und Sprachwissenschaft. Berlin 1871 (2 ed. 1881).

VASCONCELLOS, R. Fala, escuta e escrita nas produções de uma criança com Paralisia Cerebral. In: LIER-DEVITTO, M.F. \& ARANTES, L. (org.). Aquisição, Patologias e Clínicas de Linguagem. 1ed. São Paulo: EDUC/PUCSP, 2006, p. 227-234.

VASCONCELLOS, R. Organismo e Sujeito uma diferença sensível nas paralisias cerebrais. 2010. 130f. (Doutorado em Linguística Aplicada e Estudos da Linguagem) - Pontifícia Universidade Católica de São Paulo, São Paulo. Inédito. 
VOCARO, A. Incidencia da matriz simbolizante no organismo: condição necessária ao advento da fala, 1999. Disponível em http://www.freudlacan.com/Champs_specialises/Presentation/ Motricité et Psychomotricité.

VOCARO, A. Gestos que descarrilham. In: LEITE, N. (org.). Corpolinguagem - Gestos e Afetos. Campinas: Mercado das Letras, 2003, p. 125-140. 